Article

\title{
Associations between Serum Betaine, Methyl-Metabolizing Genetic Polymorphisms and Risk of Incident Type 2 Diabetes: A Prospective Cohort Study in Community-Dwelling Chinese Adults
}

\author{
Xiaoting Lu ${ }^{1}$, Rongzhu Huang ${ }^{1}$, Shuyi Li ${ }^{1}$, Aiping Fang ${ }^{1,2}$, Yuming Chen ${ }^{2,3}{ }^{\mathbb{D}}$, Si Chen ${ }^{1}$, Fan Wang ${ }^{1}$, \\ Xinlei Lin ${ }^{1}\left(\mathbb{D}\right.$, Zhaoyan Liu ${ }^{1,2, *}$ and Huilian Zhu ${ }^{1,2, *}$
}

1 Department of Nutrition, School of Public Health, Sun Yat-sen University, Guangzhou 510080, China; luxt3@mail2.sysu.edu.cn (X.L.); huangrzh9@mail2.sysu.edu.cn (R.H.); lishy45@mail2.sysu.edu.cn (S.L.); fangaip@mail.sysu.edu.cn (A.F.); chens37@mail2.sysu.edu.cn (S.C.); wangf286@mail2.sysu.edu.cn (F.W.); linxlei3@mail2.sysu.edu.cn (X.L.)

2 Guangdong Provincial Key Laboratory of Food, Nutrition and Health, School of Public Health, Sun Yat-sen University, Guangzhou 510080, China; chenyum@mail.sysu.edu.cn

3 Department of Medical Statistics \& Epidemiology, School of Public Health, Sun Yat-sen University, Guangzhou 510080, China

* Correspondence: liuzhy235@mail.sysu.edu.cn (Z.L.); zhuhl@mail.sysu.edu.cn (H.Z.); Tel.: +86-020-8733-5875 (Z.L.); +86-020-8733-1811 (H.Z.)

Citation: Lu, X.; Huang, R.; Li, S.; Fang, A.; Chen, Y.; Chen, S.; Wang, F.; Lin, X.; Liu, Z.; Zhu, H. Associations between Serum Betaine,

Methyl-Metabolizing Genetic Polymorphisms and Risk of Incident Type 2 Diabetes: A Prospective Cohort Study in

Community-Dwelling Chinese Adults. Nutrients 2022, 14, 362. https://doi.org/10.3390/ nu14020362

Academic Editor: Lu Cai

Received: 6 December 2021

Accepted: 11 January 2022

Published: 15 January 2022

Publisher's Note: MDPI stays neutral with regard to jurisdictional claims in published maps and institutional affiliations.

Copyright: (C) 2022 by the authors. Licensee MDPI, Basel, Switzerland. This article is an open access article distributed under the terms and conditions of the Creative Commons Attribution (CC BY) license (https:// creativecommons.org/licenses/by/ $4.0 /)$.

\begin{abstract}
Previous studies have explored associations between betaine and diabetes, but few have considered the effects of genes on them. We aimed to examine associations between serum betaine, methyl-metabolizing genetic polymorphisms and the risk of type 2 diabetes in Chinese adults. This prospective study comprised 1565 subjects aged 40-75 without type 2 diabetes at baseline. Serum betaine was measured by high-performance liquid chromatography tandem mass spectrometry. Genotyping of methyl-metabolizing genes was detected by Illumina ASA-750K arrays. Cox proportional hazards model was used to estimate hazard ratios (HRs) and 95\% confidence intervals (CIs). During a median of 8.9 years of follow-up, 213 participants developed type 2 diabetes. Compared with participants in the lowest quartile of serum betaine, those in the highest quartile had lower risk of type 2 diabetes, adjusted HRs $(95 \% \mathrm{CIs})$ was $0.46(0.31,0.69)$. For methylenetetrahydrofolate reductase (MTHFR) G1793A (rs2274976) and MTHFR A1298C (rs1801131), participants carrying $1793 \mathrm{GA}+\mathrm{AA}$ and 1298AC + CC had lower risk of type 2 diabetes. Interactions of serum betaine and genotype of MTHFR G1793A and MTHFR A1298C could be found influencing type 2 diabetes risk. Our findings indicate that higher serum betaine, mutations of MTHFR G1793A and A1298C, as well as the joint effects of them, are associated with lower risk of type 2 diabetes.
\end{abstract}

Keywords: betaine; type 2 diabetes; methylenetetrahydrofolate reductase; methyl-metabolizing enzyme; single nucleotide polymorphisms

\section{Introduction}

Diabetes is a worldwide health problem with an estimated 463 million adults suffering from this disease in 2019 [1]. It is not only the seventh leading cause of death globally, but also a major cause of heart attacks, stroke, kidney failure, lower limb amputation and blindness [2]. Type 2 diabetes is the most common subtype, accounting for $90-95 \%$ of diabetes cases [3]. Previous studies have found that some modifiable factors such as nutrition and lifestyle are associated with the onset of type 2 diabetes [4]. However, investigation of circulating specific nutrients on risk of type 2 diabetes has been limited.

Betaine, also known as trimethylglycine, serves as an important methyl donor in homocysteine methylation in one-carbon metabolism [5]. It has been found that people with 
diabetes had lower serum betaine levels [6] and disturbed betaine metabolism [7]. However, results from epidemiology studies determined that the associations between betaine and the risk of diabetes are inconsistent [8-12]. One research from the PREVEND (Prevention of Renal and Vascular End-Stage Disease) Study reported that high plasma betaine is associated with low incident type 2 diabetes [11]. Another large prospective cohort study found null associations between dietary betaine intake and the risk of type 2 diabetes [12]. Moreover, few studies have explored associations between serum betaine and incident type 2 diabetes in Chinese population, which has the largest number of people with diabetes in the world, accounting for around $25 \%$ of diabetes cases [1].

Circulating betaine may be influenced by several methyl-metabolizing enzymes involved in one-carbon cycle. Catalyzed by choline dehydrogenase ( $\mathrm{CHDH})$ or betainehomocysteine methyltransferase (BHMT), respectively, betaine can be increased by synthesizing from choline pathway, or decreased by transmitting methyl groups to methionine. Owing to the overlap of betaine metabolism and folate metabolism, circulating betaine levels can also be influenced by methylenetetrahydrofolate reductase (MTHFR), which is a key enzyme in folate metabolism $[13,14]$. Associations between MTHFR and both diabetic complications or hereditary diseases have been discussed in previous studies $[15,16]$, but few of them are focused on MTHFR and type 2 diabetes. Thus, due to the discrepancies of genes and ethnicity between China and other countries, whether the association between circulating betaine and type 2 diabetes risk in Chinese population is similar with other populations or not remains unclear. Moreover, previous studies have only explored relationships between type 2 diabetes and either betaine or MTHFR, investigations of the joint association of them on type 2 diabetes are scant.

Therefore, in this study, our aims were as follows: (1) to examine the relationship between serum betaine levels, relevant methyl-metabolizing enzymes genetic polymorphisms and the risk of incident type 2 diabetes among a large sample size of Chinese adults in Guangzhou Nutrition and Health Study (GNHS); and (2) to explore whether there is a joint association between serum betaine and relevant methyl-metabolizing enzymes genetic polymorphisms with risk of incident type 2 diabetes.

\section{Material and Methods}

\subsection{Design and Study Population}

This study was carried out within the GNHS, an ongoing, community-based prospective cohort study designed to investigate nutrition-related factors associated with risk of chronic diseases, including metabolic diseases and bone health. Detailed protocols of GNHS have been described previously [17]. From 2008 to 2010, 3169 residents aged 40 to 75 years who had been living in Guangzhou for more than five years were successfully recruited via advertisements, posters, health talks and referrals in local communities. Participants returned for follow-up every three years approximately and the third follow-up visit was finished for all participants till 30 April 2019. Study protocol was approved by the Ethics Committee of the School of Public Health of Sun Yat-sen University and was registered at ClinicalTrials.gov (NCT03179657). Written informed consent was provided by each participant before enrollment.

In this analysis, participants were excluded if they had serious diseases (including cancer, stroke, liver cirrhosis and chronic renal failure. $n=20$ ), had diabetes at baseline $(n=193)$, had no serum betaine measurement data $(n=873)$, had no fasting glucose or glycated hemoglobin $\left(\mathrm{HbA}_{1 \mathrm{c}}\right)$ measurement data $(n=49)$, had extreme energy intake $(<500$ or $>3500$ and $<800$ or $>4000 \mathrm{kcal} /$ day for females and males, respectively. $n=36$ ) and lost to follow-up ( $n=433$, follow-up rate was $86.3 \%$ ). The process of participant selection is shown in Figure 1. Finally, 1565 participants were included in the present analysis, of whom 1134 had detected methyl-metabolizing enzymes genetic polymorphisms. The included participants did not differ by most baseline characteristics from those excluded from the analysis (Table S1). 


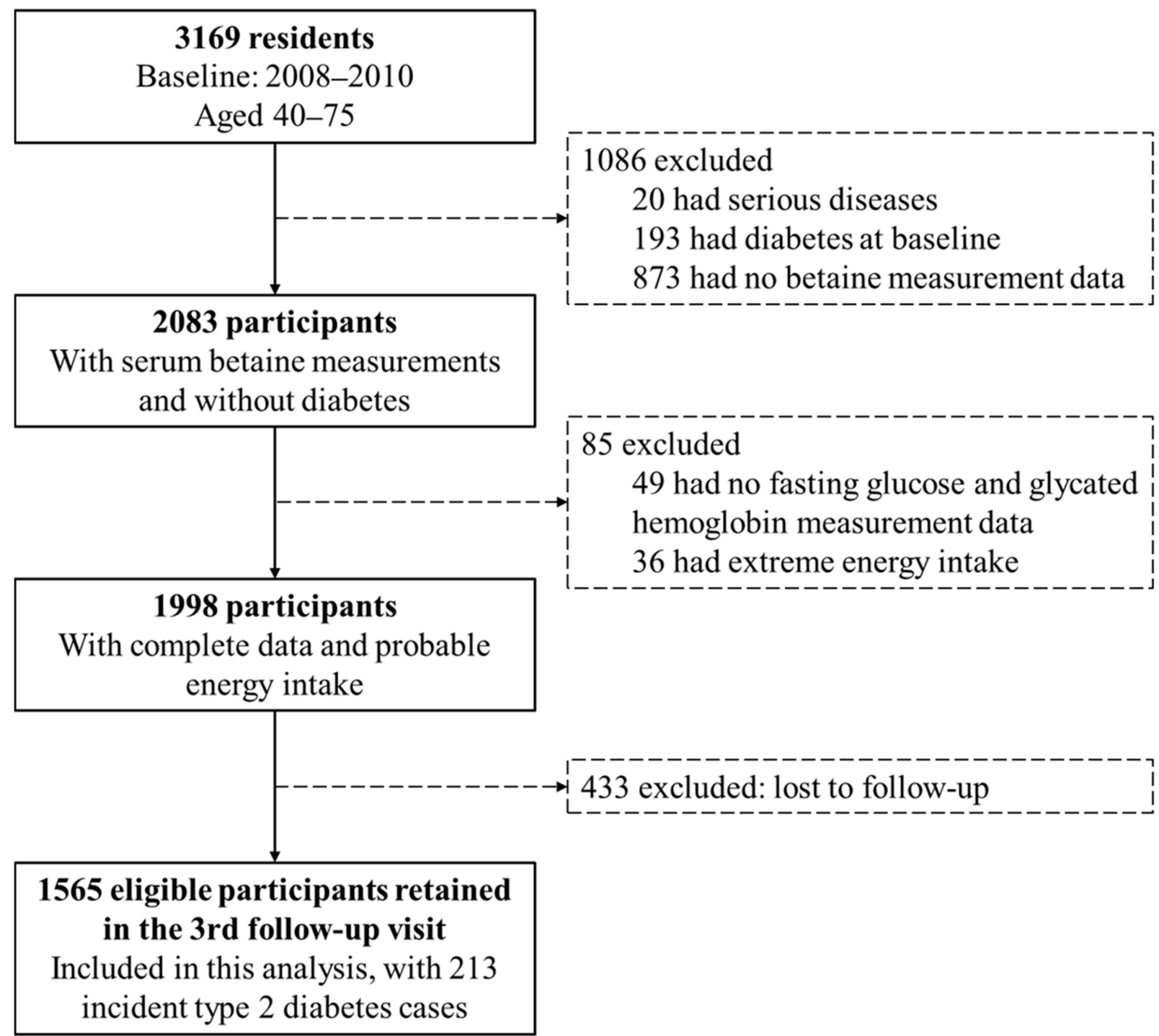

Figure 1. Flowchart of selection of participants from the Guangzhou Nutrition and Health Study.

\subsection{Measurement of Serum Betaine Concentrations}

Fasting blood samples were drawn at baseline and were centrifuged, isolated, and stored at $-80^{\circ} \mathrm{C}$ until analysis. Serum betaine concentrations were measured by highperformance liquid chromatography tandem mass spectrometry (HPLC-MS/MS) (Agilent 6400 Series Triple Quad LCMS, Santa Clara, CA, USA) [18]. Sixty microliters of either the serum samples or standards were added with $100 \mu \mathrm{L}$ of acetonitrile containing $10 \mu \mathrm{M}$ internal standards [d9-betaine (Sigma-Aldrich, St. Louis, MO, USA)]. Samples were centrifuged for $10 \mathrm{~min}$ at $13,000 \times g$ to precipitate proteins and then the supernatants were moved into spin columns and centrifuged again for $2 \mathrm{~min}$ at $3000 \times g$ to filter impurities. Finally, the remaining supernatant was transferred to sealed autosampler glass vials, injected into a normal-phase silica column $(2.1 \mathrm{~mm} \times 100 \mathrm{~mm}, 5 \mu \mathrm{M})$ by a robotic device and then equilibrated with $30 \%$ solution A (15 mmol/ $\mathrm{L}$ ammonium formate, $\mathrm{pH}=3.5)$ and $70 \%$ solution $\mathrm{B}$ (acetonitrile). The column was eluted at a flow rate of $0.2 \mathrm{~mL} / \mathrm{min}$ under isocratic elution. Replicative quality control samples were masked and interspersed among the samples to determine laboratory precision. The coefficient of variation for the between-run assays was $6.21 \%$. 


\subsection{DNA Extraction, Genotyping and SNP Selection}

Fasting blood samples were collected with EDTA-coated tubes at baseline and separated into plasma, buffy coat and red cells. DNA was extracted from leukocyte using the TIANamp ${ }^{\circledR}$ Blood DNA Kit according to the manufacturer's instruction and subsequently stored at $-80{ }^{\circ} \mathrm{C}$ DNA levels were determined using the Qubit quantification system (Thermo Scientific, Wilmington, DE, USA). Candidate single nucleotide polymorphisms (SNP) we selected were methyl-metabolizing relevant genes, including MTHFR G1793A (rs2274976), MTHFR A1298C (rs1801131), MTHFR C677T (rs1801133), CHDH A318C (rs9001) and BHMT G742A (rs3733890), which were finally carried out on 1134 subjects with Illumina ASA-750K arrays. Masked quality controls were performed and showed no abnormality. Minor allele frequency (MAF) of these five selected SNPs in this study are all greater than $5 \%$ among Chinese population (Table S2).

\subsection{Covariates Data Collection}

A face-to-face structured questionnaire was conducted to collect information on demographical characteristics, lifestyle and diet habits by well-trained personnel at baseline. Education was determined as less than high school, high school and college or above. Household income was grouped into three levels: $<1500,1500-3000$, and $>3000$ yuan/month/person. Smoker was participant who smoked more than 100 cigarettes in his whole life, while alcohol drinker was defined as participant who drank alcohol at least once per week continuously for more than six months of his life. Twenty-four-hour physical activity was assessed using a 19-items questionnaire with the mean metabolic equivalent for activities including occupation, leisure sedentary activity, housework, transportation and physical exercise [19]. Dietary information over the past year was collected using a validated 79-items semi-quantitative food frequency questionnaire [20]. Dietary energy intake (kcal/day) was calculated according to the China Food Composition Database, 2009 [21].

Anthropometric measurements including waist circumference and hip circumference were collected at baseline by experienced research staff using the same calibrated equipment and methods according to standard procedure. Ratio of waist to hip circumference (WHR) was calculated as waist circumference $(\mathrm{cm}) /$ hip circumference $(\mathrm{cm})$.

\subsection{Study Outcomes}

Incident type 2 diabetes was the primary endpoint in this analysis and was ascertained up to 30 April 2019. Participants who were with fasting blood glucose concentration $\geq$ $7.0 \mathrm{mmol} / \mathrm{L}(126 \mathrm{mg} / \mathrm{dL}), \mathrm{HbA}_{1 \mathrm{c}}$ concentration $\geq 6.5 \%$ ( $\left.48 \mathrm{mmol} / \mathrm{mol}\right)$, or self-reported diabetes medications during follow-up visits were considered to have type 2 diabetes, otherwise were considered free of type 2 diabetes. Cutoff values about glucose indexes were ascertained according to the American Diabetes Association criteria for diagnosis [3].

\subsection{Statistical Analyses}

Participants were divided into four groups according to sex-specific quartiles (Q1-Q4) of serum betaine levels, except for analyses stratified by sex. Differences as well as linear trends among baseline demographic, anthropometric and lifestyle characteristics were compared across quartiles of betaine levels by one-way ANOVA or Kruskal-Wallis tests for continuous variables as appropriate and Pearson's Chi-Squared tests for categorical variables. Hardy-Weinberg equilibrium was calculated to evaluate the genotype distribution by Pearson's Chi-Squared tests.

Cox proportional hazards models were performed to examine the relationship between both serum betaine levels and selected SNPs, and the risk of type 2 diabetes without adjustment in model 1 . Non-modifiable factors, including age (continuous) and sex (females, males), were adjusted in model 2. Further adjustments were conducted for modifiable risk factors of type 2 diabetes, including smoking status (non-smoker, smoker), alcohol drinking (non-alcohol drinker, alcohol drinker), WHR (continuous), physical activity (continuous), energy intake (continuous) in model 3. Hazard ratios (HRs) and 95\% confidence intervals 
(CIs) were calculated with the bottom quartile as the reference. Proportional-hazards assumption was satisfied by including the cross-products of quartiles of serum betaine and time $(p=0.245)$. Linear trends were calculated by assigning quartiles of serum betaine as continuous variables in the models. Non-linearity was performed with restricted cubic splines [22] and no significance was found $(p=0.192)$. Stratified analysis was conducted to examine whether the relationship between quartiles of serum betaine and risk of type 2 diabetes was different in genotypes of various SNPs. Interactions were therefore estimated in multivariate models by including the multiplicative interaction terms. Spearman's correlation analyses were carried out to explore relationships between serum betaine and SNPs, and all of the correlation coefficients calculated were less than 0.1 (Table S3). Covariates with missing data were imputed by the multiple imputation method.

Statistical analyses were performed using SPSS version 25.0 for windows (IBM Corp., Armonk, NY, USA) or Stata software version 15.0 (StataCorp., College Station, TX, USA). All tests were two-sided and $p<0.05$ was considered statistically significant.

\section{Results}

\subsection{Baseline Characteristics of Study Participants}

Of the 1565 participants at baseline, there were 1084 (69.3\%) females. Mean age was $57.4 \pm 4.9$ years. Table 1 lists the basic characteristics by sex-specific quartiles of serum betaine levels at baseline. Participants in the highest quartiles of serum betaine had lower WHR compared with participants in the lowest quartile ( $p$-trend $=0.014)$. Education levels of the participants were different among quartiles of serum betaine, but no linear trend was found ( $p$-trend $=0.341$ ). Other characteristics including sex, energy intake, physical activity, household income, smoking status, and alcohol drinking did not show significantly difference by quartiles of serum betaine.

Table 1. Baseline characteristics by sex-specific quartiles of serum betaine levels ${ }^{1}$.

\begin{tabular}{|c|c|c|c|c|c|c|}
\hline & \multicolumn{4}{|c|}{ Sex-Specific Quartiles of Serum Betaine Levels } & \multirow{2}{*}{$p$} & \multirow{2}{*}{$p$-Trend } \\
\hline & Q1 $(n=391)$ & Q2 $(n=393)$ & Q3 $(n=391)$ & $\mathrm{Q} 4(n=390)$ & & \\
\hline \multicolumn{7}{|l|}{ Serum betaine, $\mu \mathrm{mol} / \mathrm{L}$} \\
\hline Females & $25.60 \pm 7.74$ & $41.58 \pm 2.97$ & $50.72 \pm 2.91$ & $68.90 \pm 13.71$ & \multirow[b]{2}{*}{$<0.001$} & \multirow[b]{2}{*}{$<0.001$} \\
\hline Males & $31.47 \pm 8.50$ & $48.35 \pm 3.14$ & $58.73 \pm 2.98$ & $77.02 \pm 12.32$ & & \\
\hline Age, years & $57.59 \pm 4.97$ & $57.47 \pm 4.92$ & $57.69 \pm 5.09$ & $57.26 \pm 4.91$ & 0.659 & 0.504 \\
\hline WHR & $0.88 \pm 0.07$ & $0.89 \pm 0.06$ & $0.88 \pm 0.06$ & $0.87 \pm 0.07$ & 0.002 & 0.014 \\
\hline Energy intake, kcal/day & $1829.86 \pm 534.72$ & $1814.73 \pm 480.77$ & $1827.31 \pm 507.30$ & $1819.52 \pm 489.09$ & 0.973 & 0.872 \\
\hline Physical activity, MET $\times$ hours/day & $25.83 \pm 6.86$ & $25.50 \pm 7.25$ & $25.84 \pm 7.85$ & $25.68 \pm 6.65$ & 0.901 & 0.939 \\
\hline Females & $271(69.3)$ & $272(69.2)$ & $270(69.1)$ & $271(69.5)$ & 0.999 & 0.971 \\
\hline Education levels & & & & & 0.043 & 0.341 \\
\hline Less than high school & $122(31.2)$ & $112(28.5)$ & $124(31.7)$ & $105(26.9)$ & & \\
\hline High school & $161(41.2)$ & $181(46.1)$ & $183(46.8)$ & $205(52.6)$ & & \\
\hline College or above & $108(27.6)$ & $100(25.4)$ & $84(21.5)$ & $80(20.5)$ & & \\
\hline Household income, yuan/month/person & & & & & 0.786 & 0.624 \\
\hline$<1500$ & 147 (37.6) & $127(32.3)$ & $136(34.8)$ & $139(35.6)$ & & \\
\hline $1500-3000$ & $176(45.0)$ & $183(46.6)$ & $179(45.8)$ & $175(44.9)$ & & \\
\hline$\geq 3000$ & $68(17.4)$ & $83(21.1)$ & $76(19.4)$ & $76(19.5)$ & & \\
\hline Smoking status & & & & & 0.985 & 0.702 \\
\hline Non-smoker & $329(84.1)$ & $332(84.5)$ & $331(84.7)$ & $332(85.1)$ & & \\
\hline Smoker & $62(15.9)$ & $61(15.5)$ & $60(15.3)$ & $58(14.9)$ & & \\
\hline Alcohol drinking & & & & & 0.247 & 0.196 \\
\hline Non-alcohol drinker & $364(93.1)$ & $362(92.1)$ & $373(95.4)$ & $368(94.4)$ & & \\
\hline Alcohol drinker & $27(6.9)$ & $31(7.9)$ & $18(4.6)$ & $22(5.6)$ & & \\
\hline
\end{tabular}

${ }^{1}$ Data are mean \pm SD or $n(\%)$. Abbreviations: MET, metabolic equivalent tasks; 1 , first quartile; $\mathrm{Q} 2$, second quartile; Q3, third quartile; Q4, fourth quartile; WHR, ratio of waist to hip circumference.

\subsection{Serum Betaine and Risk of Incident Type 2 Diabetes}

During 12,168 person years (median follow-up time: 8.9 years) of follow-up, 213 cases (139 of which were females, $65.3 \%$ ) of type 2 diabetes were identified. Associations between sex-specific quartiles of serum betaine and type 2 diabetes were presented in Table 2. Numbers of incident cases and incidence rates of type 2 diabetes were highest in the 
bottom quartile and lowest in the fourth quartile of serum betaine. An inverse association between serum betaine levels and type 2 diabetes incidence was found with a HR of 0.45 (95\%CI: 0.30-0.66, p-trend < 0.001) at the highest quartile compared to the first quartile without adjustment. In multivariable analyses with adjustment for non-modifiable factors, including age and sex, compared with the first quartile of serum betaine, the adjusted $\mathrm{HR}$ in the highest quartile was 0.45 (95\%CI: $0.30-0.67, p$-trend $<0.001)$. The association remained statistically significant after additional adjustment for modifiable risk factors of type 2 diabetes, including smoking status, alcohol drinking, WHR, physical activity and energy intake, and the fully adjusted HR in the highest quartile was 0.46 (95\%CI: 0.31-0.69, $p$-trend $<0.001)$ in comparison with the lowest quartile of serum betaine. Consistent results were found in 1134 subjects with SNPs data (Table S4). Associations of serum betaine levels and type 2 diabetes were similar in females and males $(p$-interaction $=0.806)$.

Table 2. Hazard ratios (HRs) and 95\% confidence intervals (CIs) of type 2 diabetes according to sex-specific quartiles of serum level of betaine $(n=1565)$.

\begin{tabular}{|c|c|c|c|c|c|}
\hline & \multicolumn{5}{|c|}{ Sex-Specific Quartiles of Serum Betaine Levels } \\
\hline & Q1 $(n=391)$ & Q2 $(n=393)$ & Q3 $(n=391)$ & Q4 $(n=390)$ & $p$-Trend \\
\hline Number of cases & 76 & 58 & 43 & 36 & - \\
\hline Person years at risk & 2915.77 & 3063.16 & 3091.28 & 3097.66 & - \\
\hline Model $1^{1}$ & 1.00 (ref) & $0.73(0.52,1.03)$ & $0.53(0.37,0.78)$ & $0.45(0.30,0.66)$ & $<0.001$ \\
\hline Model 22 & 1.00 (ref) & $0.74(0.52,1.04)$ & $0.54(0.37,0.78)$ & $0.45(0.30,0.67)$ & $<0.001$ \\
\hline Model $3^{3}$ & 1.00 (ref) & $0.68(0.48,0.96)$ & $0.55(0.38,0.80)$ & $0.46(0.31,0.69)$ & $<0.001$ \\
\hline
\end{tabular}

${ }^{1}$ Unadjusted. ${ }^{2}$ Adjusted for non-modifiable factors, including age (continuous) and sex (females, males). ${ }^{3}$ Adjusted additionally for modifiable factors, including smoking status (non-smoker, smoker), alcohol drinking (non-alcohol drinker, alcohol drinker), WHR (continuous), physical activity (continuous), energy intake (continuous). Abbreviations: Q1, first quartile; Q2, second quartile; Q3, third quartile; Q4, fourth quartile.

\subsection{Methyl-Metabolizing Enzymes Genetic Polymorphisms and Incident of Type 2 Diabetes}

Basic characteristics of five selected SNPs of methyl-metabolizing enzymes are presented in Table S2. The frequencies of the minor alleles were $12.3 \%, 22.3 \%, 25.1 \%, 33.2 \%$, and 35.7\% for MTHFR G1793A, MTHFR A1298C, MTHFR C677T, CHDH A318C and BHMT G742A, respectively. All genotype distributions were in the Hardy-Weinberg equilibrium $(p>0.05)$.

The associations of these SNPs with type 2 diabetes risk are shown in Table 3. Compared with normal type genotype (GG), participants who carry heterozygous or homozygous variants (GA and AA) of MTHFR G1793A showed a lower incident risk of type 2 diabetes after full adjustments (HR: 0.54; 95\%CI: 0.35, 0.84). Compared with genotypes without mutation (AA) of MTHFR A1298C, a significant decreased risk was observed among participants who carry heterozygous or homozygous variants (AC and CC), the fully adjusted HR was $0.61(95 \% C I: 0.43,0.86)$. The other three SNPs did not show significant associations with type 2 diabetes risk.

Table 3. Hazard ratios (HRs) and 95\% confidence intervals (CIs) of type 2 diabetes according to genotype of five selected genetic variants $(n=1134)$.

\begin{tabular}{ccc}
\hline & & Genotype $(\boldsymbol{n}=\mathbf{1 1 3 4})$ \\
\hline & Non-Mutated Group & Heterozygous or Homozygous Mutated Group \\
\hline MTHFR G1793A (rs2274976) & GG & GA + AA \\
Cases $/ n$. & $134 / 878$ & $24 / 256$ \\
Model 1 & $1.00(\mathrm{ref})$ & $0.59(0.38,0.92)$ \\
Model 2 $^{2}$ & $1.00(\mathrm{ref})$ & $0.60(0.39,0.92)$ \\
Model 3 $^{3}$ & $1.00(\mathrm{ref})$ & $0.54(0.35,0.84)$ \\
\hline
\end{tabular}


Table 3. Cont.

\begin{tabular}{|c|c|c|c|c|c|c|c|}
\hline & & \multicolumn{6}{|c|}{ Genotype $(n=1134)$} \\
\hline & & \multicolumn{3}{|c|}{ Non-Mutated Group } & \multicolumn{3}{|c|}{ Heterozygous or Homozygous Mutated Group } \\
\hline MTHFR A12 & 801131) & \multicolumn{3}{|c|}{ AA } & \multicolumn{3}{|c|}{$\mathrm{AC}+\mathrm{CC}$} \\
\hline Cas & & \multicolumn{3}{|c|}{$110 / 686$} & \multicolumn{3}{|c|}{$48 / 448$} \\
\hline Mo & & \multicolumn{3}{|c|}{1.00 (ref) } & \multicolumn{3}{|c|}{$0.65(0.46,0.91)$} \\
\hline Mo & & \multicolumn{3}{|c|}{1.00 (ref) } & \multicolumn{3}{|c|}{$0.64(0.46,0.90)$} \\
\hline Mo & & \multicolumn{3}{|c|}{1.00 (ref) } & \multicolumn{3}{|c|}{$0.61(0.43,0.86)$} \\
\hline MTHFR C67 & 301133) & \multicolumn{3}{|c|}{ CC } & \multicolumn{3}{|c|}{$\mathrm{CT}+\mathrm{TT}$} \\
\hline Cas & & \multicolumn{3}{|c|}{$81 / 645$} & \multicolumn{3}{|c|}{$77 / 489$} \\
\hline Moc & & \multicolumn{3}{|c|}{1.00 (ref) } & \multicolumn{3}{|c|}{$1.31(0.96,1.79)$} \\
\hline Mo & & \multicolumn{3}{|c|}{1.00 (ref) } & \multicolumn{3}{|c|}{$1.30(0.95,1.78)$} \\
\hline Moc & & \multicolumn{3}{|c|}{1.00 (ref) } & \multicolumn{3}{|c|}{$1.33(0.97,1.81)$} \\
\hline $\mathrm{CHDH} \mathrm{A3}$ & $9001)$ & \multicolumn{3}{|c|}{$\mathrm{AA}$} & \multicolumn{3}{|c|}{$\mathrm{AC}+\mathrm{CC}$} \\
\hline Cas & & & $70 / 503$ & & & $88 / 631$ & \\
\hline Mo & & & 1.00 (ref) & & & $1.01(0.73,1$ & \\
\hline Moc & & & 1.00 (ref) & & & $1.01(0.74,1$ & \\
\hline $\mathrm{Mo}$ & & & 1.00 (ref) & & & $0.99(0.72,1$ & \\
\hline BHMT G742 & 33890) & & GG & & & $\mathrm{GA}+\mathrm{A}$ & \\
\hline Cas & & & $64 / 468$ & & & $94 / 666$ & \\
\hline Mo & & & 1.00 (ref) & & & $1.01(0.74,1$ & \\
\hline Moc & & & 1.00 (ref) & & & $1.02(0.74,1$ & \\
\hline Moc & & & 1.00 (ref) & & & $0.91(0.66,1$ & \\
\hline & & $\begin{array}{l}{ }^{1} \text { Unadjusted. }{ }^{2} \\
{ }^{3} \text { Adjusted additi } \\
\text { (non-alcohol drin } \\
\text { ous). Abbreviatio } \\
\text { methylenetetrahy }\end{array}$ & $\begin{array}{l}\text { djusted for non- } \\
\text { nally for modifiab } \\
\text { r, alcohol drinker } \\
\text { s: } B H M T \text {, betaine } \\
\text { rofolate reductase }\end{array}$ & $\begin{array}{l}\text { nodifiable factors } \\
\text { factors, includin } \\
\text { WHR (continuou } \\
\text { nomocysteine met }\end{array}$ & $\begin{array}{l}\text {, including age (c } \\
\text { g smoking status (1 } \\
\text { is), physical activit } \\
\text { thyltransferase; } C\end{array}$ & $\begin{array}{l}\text { continuous) a } \\
\text { non-smoker, s } \\
\text { y (continuous } \\
\text { IDH, choline }\end{array}$ & $\begin{array}{l}\text { x (females, males) } \\
\text { ), alcohol drinking } \\
\text { gy intake (continu } \\
\text { rogenase; } M T H F R\end{array}$ \\
\hline & & 3.4. Interaction & between Serum & Betaine Levels a & nd Genetic Poly & morphisms & \\
\hline & & $\begin{array}{l}\text { The influ } \\
\text { methyl-metab } \\
\text { interactions w } \\
\text { genotype of } N \\
\text { ( } p \text {-interaction } \\
\text { stronger assoc } \\
\text { carried heterc } \\
\text { was observed }\end{array}$ & $\begin{array}{l}\text { nce of serum b } \\
\text { lizing enzyme } \\
\text { re statistically } \\
\text { HFR G1793A } \\
0.05) \text {. When s } \\
\text { ations of serum } \\
\text { ygous or hom } \\
\text { etween other }\end{array}$ & $\begin{array}{l}\text { etaine levels } \mathrm{fo} \\
\text { genetic polyn } \\
\text { gnificant betw } \\
\text { nd MTHFR A] } \\
\text { ratified by gen } \\
\text { betaine levels } \\
\text { ozygous varia } \\
\text { hree SNPs and }\end{array}$ & $\begin{array}{l}\text { or type } 2 \text { diabe } \\
\text { norphisms is sh } \\
\text { een sex-specifi } \\
1298 \mathrm{C} \text { on associ } \\
\text { otype of } M T H \\
\text { with type } 2 \text { di } \\
\text { nts. No signifi } \\
\text { quartiles of se }\end{array}$ & $\begin{array}{l}\text { tes across s } \\
\text { nown in Tal } \\
\text { c quartiles c } \\
\text { lations with } \\
\text { ER G1793A } \\
\text { abetes risk } \\
\text { cant multip } \\
\text { rum betain }\end{array}$ & $\begin{array}{l}\text { of genotype of } \\
\text { Multiplicative } \\
\text { um betaine and } \\
2 \text { diabetes risk } \\
\text { ITHFR A1298C } \\
\text { found in those } \\
\text { tive interaction }\end{array}$ \\
\hline & & $\begin{array}{l}\text { Table 4. Adjust } \\
\text { to quartiles of } s\end{array}$ & $\begin{array}{l}\text { hazard ratios } \\
\text { um betaine leve }\end{array}$ & $\begin{array}{l}\text { IRs) and } 95 \% \text { co } \\
\text { ls within each si }\end{array}$ & $\begin{array}{l}\text { nfidence interval } \\
\text { ubgroup by relat }\end{array}$ & $\begin{array}{l}\mathrm{s}(\mathrm{CIs}) \text { of typ } \\
\text { ed genetic } \mathrm{v}\end{array}$ & $\begin{array}{l}\text { iabetes according } \\
\text { ts }(n=1134)^{1} \text {. }\end{array}$ \\
\hline & 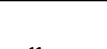 & & Quartile of Ser & Im Betaine Levels & & & Intan \\
\hline & $n$ & $\mathrm{Q} 1(n=289)$ & $\mathrm{Q} 2(n=280)$ & Q3 $(n=286)$ & $\mathrm{Q} 4(n=279)$ & & $p$-Interaction \\
\hline MTHFR G179 & 74976) & & & & & & 0.017 \\
\hline GG & 878 & 1.00 (ref) & $0.71(0.47,1.08)$ & $0.47(0.29,0.76)$ & $0.40(0.23,0.68)$ & $<0.001$ & \\
\hline $\mathrm{GA}+\mathrm{AA}$ & 256 & 1.00 (ref) & $0.34(0.10,1.10)$ & $0.35(0.11,1.11)$ & $0.33(0.11,0.97)$ & 0.039 & \\
\hline MTHFR A129 & 1131) & & & & & & 0.007 \\
\hline $\mathrm{AA}$ & 686 & 1.00 (ref) & $0.77(0.48,1.23)$ & $0.51(0.30,0.86)$ & $0.38(0.21,0.70)$ & $<0.001$ & \\
\hline $\mathrm{AC}+\mathrm{CC}$ & 448 & 1.00 (ref) & $0.44(0.21,0.95)$ & $0.36(0.16,0.81)$ & $0.33(0.15,0.76)$ & 0.003 & \\
\hline MTHFR C677 & 1133) & & & & & & 0.086 \\
\hline $\mathrm{CC}$ & 645 & 1.00 (ref) & $0.49(0.28,0.86)$ & $0.39(0.21,0.72)$ & $0.37(0.20,0.71)$ & 0.001 & \\
\hline $\mathrm{CT}+\mathrm{TT}$ & 489 & 1.00 (ref) & $1.01(0.58,1.77)$ & $0.57(0.31,1.07)$ & $0.38(0.18,0.79)$ & 0.003 & \\
\hline $\mathrm{CHDH}$ A31 & & & & & & & 0.787 \\
\hline $\mathrm{AA}$ & 503 & 1.00 (ref) & $0.68(0.38,1.22)$ & $0.44(0.22,0.86)$ & $0.29(0.14,0.61)$ & $<0.001$ & \\
\hline$A C+C C$ & 631 & 1.00 (ref) & $0.67(0.39,1.14)$ & $0.51(0.28,0.91)$ & $0.49(0.26,0.91)$ & 0.009 & \\
\hline
\end{tabular}


Table 4. Cont.

\begin{tabular}{|c|c|c|c|c|c|c|c|}
\hline & \multirow{2}{*}{$n$} & \multicolumn{4}{|c|}{ Quartile of Serum Betaine Levels } & \multirow{2}{*}{$p$-Trend } & \multirow{2}{*}{$p$-Interaction } \\
\hline & & $\mathrm{Q} 1(n=289)$ & Q2 $(n=280)$ & Q3 $(n=286)$ & Q4 $(n=279)$ & & \\
\hline \multicolumn{2}{|c|}{ BHMT G742A (rs3733890) } & & & & & & 0.355 \\
\hline GG & 468 & 1.00 (ref) & $0.74(0.39,1.38)$ & $0.56(0.28,1.11)$ & $0.37(0.17,0.80)$ & 0.007 & \\
\hline $\mathrm{GA}+\mathrm{AA}$ & 666 & 1.00 (ref) & $0.62(0.37,1.02)$ & $0.40(0.22,0.71)$ & $0.37(0.20,0.69)$ & $<0.001$ & \\
\hline
\end{tabular}

${ }^{1}$ Adjusted for non-modifiable factors, including age (continuous) and sex (females, males), and for modifiable factors, including smoking status (non-smoker, smoker), alcohol drinking (non-alcohol drinker, alcohol drinker), WHR (continuous), physical activity (continuous), energy intake (continuous). Abbreviations: BHMT, betainehomocysteine methyltransferase; $\mathrm{CHDH}$, choline dehydrogenase; MTHFR, methylenetetrahydrofolate reductase; $\mathrm{Q} 1$, first quartile; Q2, second quartile; Q3, third quartile; Q4, fourth quartile.

The joint effects of serum betaine levels and selected SNPs (MTHFR G1793A and MTHFR A1298C) on risk of type 2 diabetes are shown in Figure 2. After adjusting for non-modifiable and modifiable risk factors of type 2 diabetes, HRs for incident risk of type 2 diabetes were $0.29(0.14,0.57)$ and $0.31(0.18,0.53)$, respectively, for participants with high serum betaine levels $(>47.82 \mu \mathrm{mol} / \mathrm{L})$ and heterozygous or homozygous variants (GA and AA for MTHFR G1793A, AC and CC for MTHFR A1298C), where the low serum betaine levels $(\leq 47.82 \mu \mathrm{mol} / \mathrm{L})$ and normal type genotype (GG for MTHFR G1793A, AA for MTHFR A1298C) was the reference category.

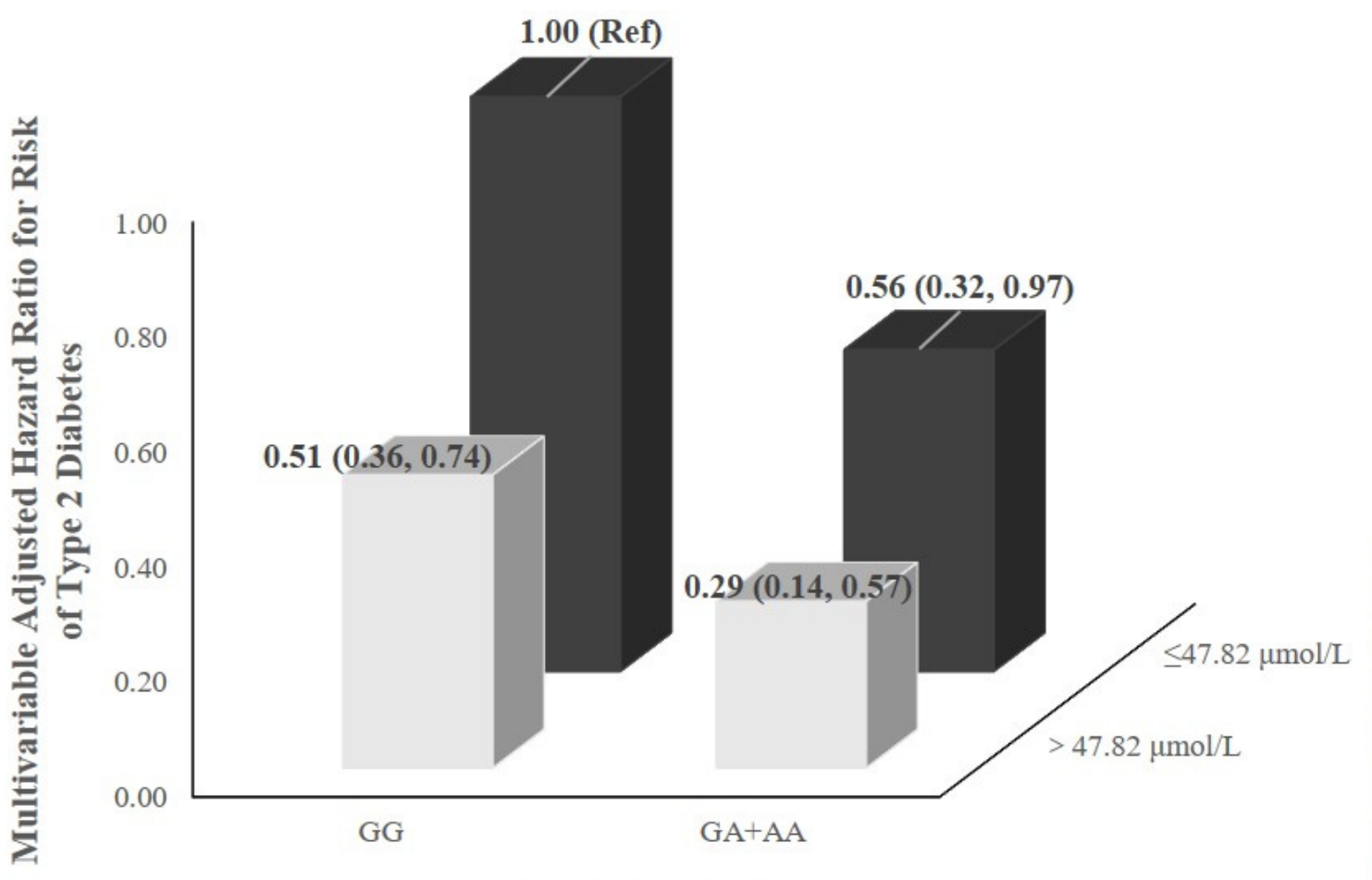

Genotype of MTHFR G1793A

Figure 2. Cont. 


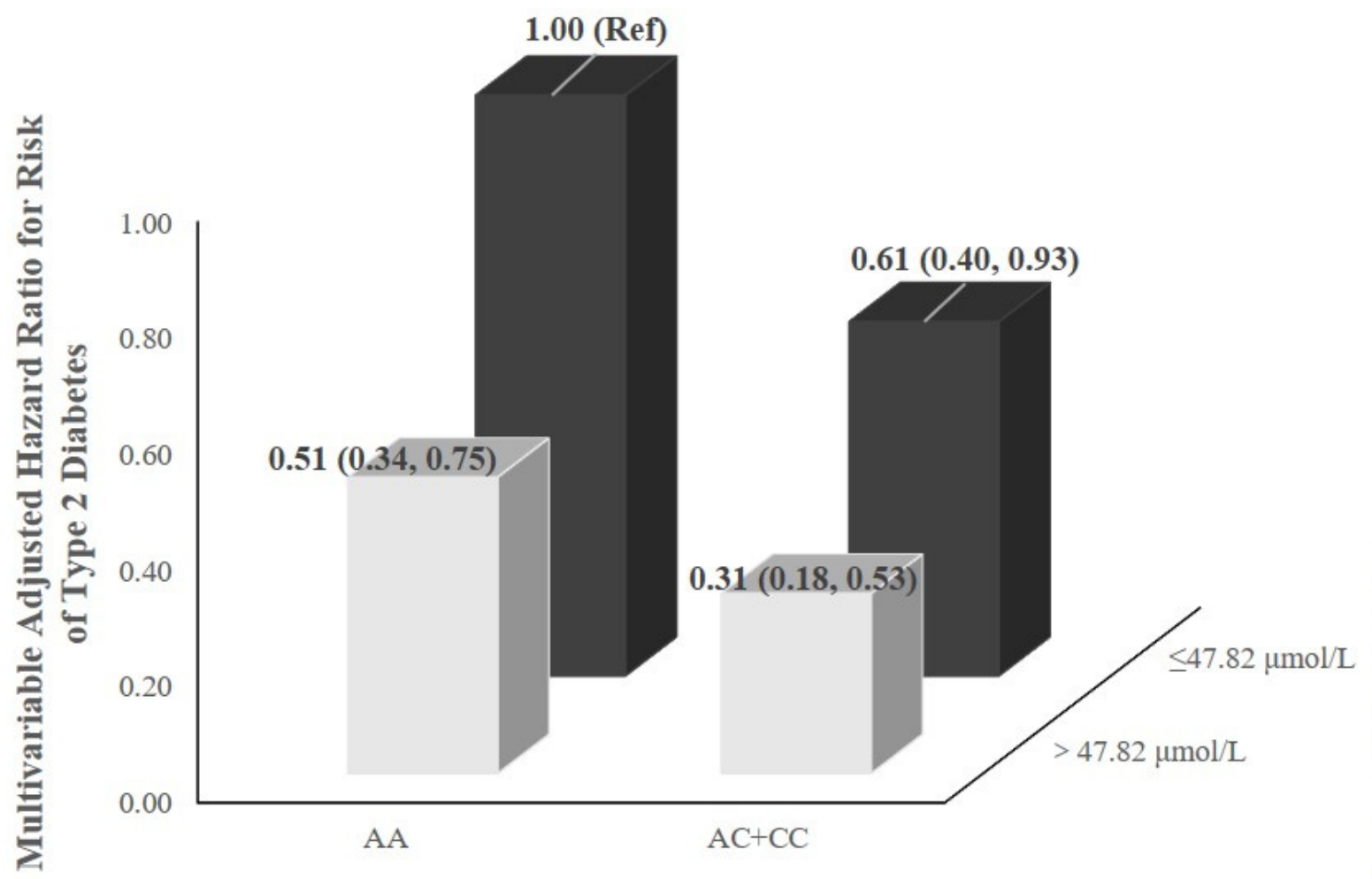

\section{Genotype of MTHFR A1298C}

Figure 2. Interaction of serum betaine and genotypes of MTHFR G1793A or A1298C on the association with risk of type 2 diabetes in the Guangzhou Nutrition and Health Study.

\section{Discussion}

In this prospective cohort study of 1565 community-dwelling Chinese adults, we observed that serum betaine levels were inversely associated with incident of type 2 diabetes after a median follow-up of 8.9 years, while participants who carry heterozygous or homozygous variants of MTHFR G1793A and MTHFR A1298C had a lower risk of incident type 2 diabetes compared with those carried normal type genotypes. The associations remained robust after adjusting for several potential confounders. Moreover, the joint effects of higher serum betaine levels and heterozygous or homozygous variants of MTHFR on reduction of type 2 diabetes risk were also observed.

Some previous studies have investigated the relationship between serum betaine and the risk of type 2 diabetes. In a cross-sectional study of a subset of the NAME (Nutrition, Aging, and Memory in Elders) study, participants with high plasma levels of betaine were associated with lower odds of diabetes after adjusting for covariates [10]. Another study found that increasing betaine levels were associated with lower risk of type 2 diabetes, which indicated that betaine was a marker of type 2 diabetes risk [4]. Similar associations could also be observed in Norwegian, Netherlandish, and Spanish populations [11,23,24]. All of these studies were conducted among American or European population, or participants with certain specific diseases, such as obesity and stable angina pectoris. In the present study carried out among apparently healthy middle-aged and elderly Chinese adults, consistent results were found between serum betaine and risk of type 2 diabetes.

Experimental studies in vitro or in vivo have demonstrated potential biological mechanisms for the relationship between betaine and glucose metabolism. Betaine supplementation not only can prevent the formation or accelerate the consumption of white fat, and therefore inhibit white fat production, but also can reduce intramyocellular lipid accumulation and relieve inflammation, subsequently improving insulin resistance [25]. Additionally, betaine supplementation may increase circulating and hepatic fibroblast growth factor 21 levels, thereby increasing whole-body energy expenditure, maintaining 
glucose homeostasis and improving insulin resistance [26]. Besides, betaine can inhibit the forkhead box $\mathrm{O} 1$ binding to thioredoxin-interacting proteins, which regulates genes involved in cellular metabolic processes and oxidative stress responses, and therefore suppress inflammation and improve insulin resistance [27].

Several genetic variants in human genes have been recognized as risk factors of type 2 diabetes [28]. MTHFR plays an important role in one-carbon cycle and DNA methylation, genetic variations of which may result in disturbances of one-carbon metabolism and DNA methylation. MTHFR G1793A and MTHFR A1298C are common missense sequence variants of MTHFR and diminish MTHFR enzymatic activity [29,30]. Previous studies have explored relationships between MTHFR and diseases such as diabetic complications, cancer or hereditary diseases, but few of them are focused on MTHFR and type 2 diabetes $[15,16,31]$. In contrast to our finding, a case-control study including 360 patients and 400 healthy subjects in Tunisia found no significant association between the genotype of MTHFR A1298C and type 2 diabetes [32]. Similar associations could be found in a Moroccan population [33]. Results of a meta-analysis, including 6 case-control studies with 852 controls and 897 cases, suggested that $1298 \mathrm{CC}$ is a risk factor for type 2 diabetes. Another case-control study including 151 patients and 136 healthy individuals discovered that variants of MTHFR A1298C were associated with the risk of type 2 diabetes in Iran's population [34]. Reasons for these discrepancies could be attributed to differences in genes, ethnicity, study design, sample sizes, as well as covariates using to adjust. Moreover, some previous studies have found that 1793A and 1298C seemed to be a protective factor in several diseases such as male infertility and breast cancer [35,36]. Evidences from a crosssectional study suggested that variants of MTHFR A1298C may protect diabetic patients with low-normal serum folate levels from developing diabetic nephropathy [15]. To some extent, these results implied that MTHFR $1793 \mathrm{G}$ and 1298A may perform a hazardous function in certain diseases. In addition, we found no association between $C H D H A 318 C$, BHMT G742A and type 2 diabetes risk. Relationships between $C H D H$ A318C, BHMT G742A, and diseases were less examined in some studies with controversial results. BHMT G742A was observed to be associated with decreased risk of colorectal adenoma [37], while no association was found between these two SNPs and breast cancer [38], and the latter was consistent with our results.

Metabolism of betaine, folate, and methionine interweaved on homocysteine in one-carbon cycle. Briefly, homocysteine utilized methyl from betaine or folate cycle to synthesize methionine, and the latter therefore generated S-adenosylmethionine, Sadenosylhomocysteine and finally homocysteine, forming a cycle of methyl metabolism [39]. In our study, we found interactions between serum betaine and genotypes of MTHFR. Individuals with high serum betaine levels and heterozygous or homozygous variants had the lowest risk of incident type 2 diabetes. Higher betaine levels could decrease the risk of type 2 diabetes through improving insulin resistance and other biological pathways [25-27]. Heterozygous or homozygous state of MTHFR may be a protective mutation in several diseases such as diabetes and cancer $[15,35]$. Betaine served as a main methyl donor in homocysteine transmethylation in the one-carbon metabolism, together with 5-methyltetrahydrofolate (5-methyl-THF), which was determined by MTHFR enzymatic activity. On the one hand, populations with MTHFR mutation were frequently accompanied by higher levels of homocysteine [30]. Reduction effects of betaine supplementation on homocysteine could also be observed in MTHFR deficient patients, and therefore this improved the prognosis of patients with neurological deterioration [40]. On the other hand, MTHFR mutation clearly reduced MTHFR enzymatic activity, and consequently decreased levels of 5-methyl-THF [30]. Previous studies had found that betaine and 5-methyl-THF were regarded as interchangeable sources of methyl groups partly [41]. These suggested an internal relation between betaine and MTHFR enzyme. Levels of circulating betaine and functional pathways it involved may be influenced by enzymatic activities of MTHFR. Further mechanisms need to be certified in future studies. 
The strengths of our study are notable. First, we perform a community-based cohort study with large sample size and long follow-up, which is able to investigate the association between serum betaine levels and the risk of incident type 2 diabetes prospectively. Second, concentrations of betaine are measured in serum by using HPLC-MS/MS, which can provide more accurate circulating levels. Third, the frequencies of alleles we selected are semblable to previous studies in the Chinese population [38,42], which confirms less selection bias in our study.

Several limitations should be considered. First, participants are middle-aged and older Chinese individuals, and therefore the generalizability of the findings using to other populations should be applied modestly. Furthermore, despite the fact that we adjusted for multiple potential confounders, including demographic and lifestyle covariate data, residual confounding cannot be ruled out completely. Finally, SNPs we selected in our study are potentially functional with reported MAF $>5 \%$ in the Chinese population. Further genome-wide association studies need to be designed to examine relationships between these SNPs and risk of type 2 diabetes.

\section{Conclusions}

In conclusion, higher serum betaine levels are associated with lower risk of type 2 diabetes in middle-aged and older adults in urban areas of southern China. Heterozygous or homozygous genotypes of MTHFR G1793A, and A1298C may be protective mutations in developing type 2 diabetes. The joint effects of higher serum betaine levels and heterozygous or homozygous genotypes of MTHFR (including MTHFR G1793A, and A1298C) on decreasing risk of type 2 diabetes can also be found. Underlying mechanisms of these complicated associations need to be further elucidated in the future.

Supplementary Materials: The following supporting information can be downloaded at: https:/ / www.mdpi.com/article/10.3390/nu14020362/s1. Table S1. Baseline characteristics by included and excluded participants; Table S2. Characteristics of the studied SNPs $(n=1134)$; Table S3 Spearman's correlation coefficients between serum betaine and the studied SNPs $(n=1134)$; Table S4 Hazard ratios (HRs) and 95\% confidence intervals (CIs) of type 2 diabetes according to sex-specific quartiles of serum level of betaine in subjects with SNPs data $(n=1134)$.

Author Contributions: Conceptualization, H.Z. and Y.C.; investigation, X.L. (Xiaoting Lu), R.H., S.L., A.F., S.C., F.W. and X.L. (Xinlei Lin); methodology, X.L. (Xiaoting Lu); writing—original draft preparation, X.L. (Xiaoting Lu); writing-review and editing, X.L. (Xiaoting Lu), Z.L. and H.Z. All authors have read and agreed to the published version of the manuscript.

Funding: This work was jointly funded by the National Natural Science Foundation of China (No. 81773415) and the Key Project of Science and Technology Program of Guangzhou, China (No. 201704020035).

Institutional Review Board Statement: The study was conducted according to the guidelines of the Declaration of Helsinki, and approved by the Ethics Committee of the School of Public Health of Sun Yat-sen University and was registered at ClinicalTrials.gov (NCT03179657).

Informed Consent Statement: Informed consent was obtained from all subjects involved in the study.

Data Availability Statement: Data described in the article are available from the corresponding author upon reasonable request.

Acknowledgments: The authors thank all of the volunteers, staff, and partner organizations participating in this study.

Conflicts of Interest: The authors declare no conflict of interest. 


\section{References}

1. International Diabetes Federation. IDF Diabetes Atlas, 9th ed.; International Diabetes Federation: Brussels, Belgium, 2019. Available online: https:/ / www.diabetesatlas.org/en/ (accessed on 5 December 2021).

2. World Health Organization. Diabetes. Available online: https://www.who.int/news-room/fact-sheets/detail/diabetes (accessed on 5 December 2021).

3. American Diabetes Association. Diagnosis and classification of diabetes mellitus. Diabetes Care 2014, 37, S81-S90. [CrossRef]

4. Walford, G.A.; Ma, Y.; Clish, C.; Florez, J.C.; Wang, T.J.; Gerszten, R.E. Metabolite profiles of diabetes incidence and intervention response in the Diabetes Prevention Program. Diabetes 2016, 65, 1424-1433. [CrossRef] [PubMed]

5. Craig, S.A. Betaine in human nutrition. Am. J. Clin. Nutr. 2004, 80, 539-549. [CrossRef] [PubMed]

6. Obeid, R.; Awwad, H.M.; Rabagny, Y.; Graeber, S.; Herrmann, W.; Geisel, J. Plasma trimethylamine N-oxide concentration is associated with choline, phospholipids, and methyl metabolism. Am. J. Clin. Nutr. 2016, 103, 703-711. [CrossRef]

7. Lever, M.; McEntyre, C.J.; George, P.M.; Slow, S.; Elmslie, J.L.; Lunt, H.; Chambers, S.T.; Parry-Strong, A.; Krebs, J.D. Extreme urinary betaine losses in type 2 diabetes combined with bezafibrate treatment are associated with losses of dimethylglycine and choline but not with increased losses of other osmolytes. Cardiovasc. Drugs Ther. 2014, 28, 459-468. [CrossRef] [PubMed]

8. Gao, X.; Wang, Y.; Sun, G. High dietary choline and betaine intake is associated with low insulin resistance in the Newfoundland population. Nutrition 2017, 33, 28-34. [CrossRef]

9. Gao, X.; Randell, E.; Tian, Y.; Zhou, H.; Sun, G. Low serum choline and high serum betaine levels are associated with favorable components of metabolic syndrome in Newfoundland population. J. Diabetes Complicat. 2019, 33, 107398. [CrossRef] [PubMed]

10. Roe, A.J.; Zhang, S.; Bhadelia, R.A.; Johnson, E.J.; Lichtenstein, A.H.; Rogers, G.T.; Rosenberg, I.H.; Smith, C.E.; Zeisel, S.H.; Scott, T.M. Choline and its metabolites are differently associated with cardiometabolic risk factors, history of cardiovascular disease, and MRI-documented cerebrovascular disease in older adults. Am. J. Clin. Nutr. 2017, 105, 1283-1290. [CrossRef]

11. Garcia, E.; Oste, M.C.J.; Bennett, D.W.; Jeyarajah, E.J.; Shalaurova, I.; Gruppen, E.G.; Hazen, S.L.; Otvos, J.D.; Bakker, S.J.L.; Dullaart, R.P.F.; et al. High Betaine, a Trimethylamine N-Oxide Related Metabolite, Is Prospectively Associated with Low Future Risk of Type 2 Diabetes Mellitus in the PREVEND Study. J. Clin. Med. 2019, 8, 1813. [CrossRef]

12. Dibaba, D.T.; Johnson, K.C.; Kucharska-Newton, A.M.; Meyer, K.; Zeisel, S.H.; Bidulescu, A. The Association of Dietary Choline and Betaine With the Risk of Type 2 Diabetes: The Atherosclerosis Risk in Communities (ARIC) Study. Diabetes Care 2020, 43, 2840-2846. [CrossRef]

13. Rhee, E.P.; Ho, J.E.; Chen, M.H.; Shen, D.; Cheng, S.; Larson, M.G.; Ghorbani, A.; Shi, X.; Helenius, I.T.; O’Donnell, C.J.; et al. A genome-wide association study of the human metabolome in a community-based cohort. Cell Metab. 2013, 18, 130-143. [CrossRef] [PubMed]

14. Ilozumba, M.N.; Cheng, T.D.; Neuhouser, M.L.; Miller, J.W.; Beresford, S.A.A.; Duggan, D.J.; Toriola, A.T.; Song, X.; Zheng, Y.; Bailey, L.B.; et al. Associations between Plasma Choline Metabolites and Genetic Polymorphisms in One-Carbon Metabolism in Postmenopausal Women: The Women's Health Initiative Observational Study. J. Nutr. 2020, 150, 2874-2881. [CrossRef]

15. Shpichinetsky, V.; Raz, I.; Friedlander, Y.; Goldschmidt, N.; Wexler, I.D.; Ben-Yehuda, A.; Friedman, G. The association between two common mutations C677T and A1298C in human methylenetetrahydrofolate reductase gene and the risk for diabetic nephropathy in type II diabetic patients. J. Nutr. 2000, 130, 2493-2497. [CrossRef]

16. de Aquino, S.N.; Hoshi, R.; Bagordakis, E.; Pucciarelli, M.G.; Messetti, A.C.; Moreira, H.; Bufalino, A.; Borges, A.; Rangel, A.L.; Brito, L.A.; et al. MTHFR rs2274976 polymorphism is a risk marker for nonsyndromic cleft lip with or without cleft palate in the Brazilian population. Birth Defects Res. A Clin. Mol. Teratol. 2014, 100, 30-35. [CrossRef]

17. Miao, Z.; Lin, J.S.; Mao, Y.; Chen, G.D.; Zeng, F.F.; Dong, H.L.; Jiang, Z.; Wang, J.; Xiao, C.; Shuai, M.; et al. Erythrocyte n-6 Polyunsaturated Fatty Acids, Gut Microbiota, and Incident Type 2 Diabetes: A Prospective Cohort Study. Diabetes Care 2020, 43, 2435-2443. [CrossRef] [PubMed]

18. Holm, P.I.; Ueland, P.M.; Kvalheim, G.; Lien, E.A. Determination of choline, betaine, and dimethylglycine in plasma by a high-throughput method based on normal-phase chromatography-tandem mass spectrometry. Clin. Chem. 2003, 49, 286-294. [CrossRef] [PubMed]

19. Ainsworth, B.E.; Haskell, W.L.; Herrmann, S.D.; Meckes, N.; Bassett, D.R., Jr.; Tudor-Locke, C.; Greer, J.L.; Vezina, J.; Whitt-Glover, M.C.; Leon, A.S. 2011 Compendium of Physical Activities: A second update of codes and MET values. Med. Sci. Sports Exerc. 2011, 43, 1575-1581. [CrossRef] [PubMed]

20. Zhang, C.X.; Ho, S.C. Validity and reproducibility of a food frequency questionnaire among Chinese women in Guangdong province. Asia Pac. J. Clin. Nutr. 2009, 18, 240-250.

21. Yang, Y.X. China Food Composition; Peking University Medical Press: Beijing, China, 2009.

22. Desquilbet, L.; Mariotti, F. Dose-response analyses using restricted cubic spline functions in public health research. Stat. Med. 2010, 29, 1037-1057. [CrossRef]

23. Svingen, G.F.; Schartum-Hansen, H.; Pedersen, E.R.; Ueland, P.M.; Tell, G.S.; Mellgren, G.; Njolstad, P.R.; Seifert, R.; Strand, E.; Karlsson, T.; et al. Prospective Associations of Systemic and Urinary Choline Metabolites with Incident Type 2 Diabetes. Clin. Chem. 2016, 62, 755-765. [CrossRef]

24. Papandreou, C.; Bullo, M.; Zheng, Y.; Ruiz-Canela, M.; Yu, E.; Guasch-Ferre, M.; Toledo, E.; Clish, C.; Corella, D.; Estruch, R.; et al. Plasma trimethylamine-N-oxide and related metabolites are associated with type 2 diabetes risk in the Prevencion con Dieta Mediterranea (PREDIMED) trial. Am. J. Clin. Nutr. 2018, 108, 163-173. [CrossRef] 
25. Du, J.; Shen, L.; Tan, Z.; Zhang, P.; Zhao, X.; Xu, Y.; Gan, M.; Yang, Q.; Ma, J.; Jiang, A.; et al. Betaine Supplementation Enhances Lipid Metabolism and Improves Insulin Resistance in Mice Fed a High-Fat Diet. Nutrients 2018, 10, 131. [CrossRef]

26. Ejaz, A.; Martinez-Guino, L.; Goldfine, A.B.; Ribas-Aulinas, F.; De Nigris, V.; Ribo, S.; Gonzalez-Franquesa, A.; Garcia-Roves, P.M.; Li, E.; Dreyfuss, J.M.; et al. Dietary Betaine Supplementation Increases Fgf21 Levels to Improve Glucose Homeostasis and Reduce Hepatic Lipid Accumulation in Mice. Diabetes 2016, 65, 902-912. [CrossRef] [PubMed]

27. Kim, D.H.; Kim, S.M.; Lee, B.; Lee, E.K.; Chung, K.W.; Moon, K.M.; An, H.J.; Kim, K.M.; Yu, B.P.; Chung, H.Y. Effect of betaine on hepatic insulin resistance through FOXO1-induced NLRP3 inflammasome. J. Nutr. Biochem. 2017, 45, 104-114. [CrossRef] [PubMed]

28. Torres, J.M.; Abdalla, M.; Payne, A.; Fernandez-Tajes, J.; Thurner, M.; Nylander, V.; Gloyn, A.L.; Mahajan, A.; McCarthy, M.I. A Multi-omic Integrative Scheme Characterizes Tissues of Action at Loci Associated with Type 2 Diabetes. Am. J. Hum. Genet. 2020, 107, 1011-1028. [CrossRef]

29. Rady, P.L.; Szucs, S.; Grady, J.; Hudnall, S.D.; Kellner, L.H.; Nitowsky, H.; Tyring, S.K.; Matalon, R.K. Genetic polymorphisms of methylenetetrahydrofolate reductase (MTHFR) and methionine synthase reductase (MTRR) in ethnic populations in Texas; a report of a novel MTHFR polymorphic site, G1793A. Am. J. Med. Genet. 2002, 107, 162-168. [CrossRef] [PubMed]

30. Weisberg, I.; Tran, P.; Christensen, B.; Sibani, S.; Rozen, R. A second genetic polymorphism in methylenetetrahydrofolate reductase (MTHFR) associated with decreased enzyme activity. Mol. Genet. Metab. 1998, 64, 169-172. [CrossRef]

31. Chen, X.L.; Wang, Y.M.; Zhao, F.; Chen, Z.; Yang, X.; Sun, C.; Gao, Y.; Yang, T.G.; Tian, G.; Chen, Y.M.; et al. Methylenetetrahydrofolate reductase polymorphisms and colorectal cancer prognosis: A meta-analysis. J. Gene Med. 2019, 21, e3114. [CrossRef] [PubMed]

32. Mtiraoui, N.; Ezzidi, I.; Chaieb, M.; Marmouche, H.; Aouni, Z.; Chaieb, A.; Mahjoub, T.; Vaxillaire, M.; Almawi, W.Y. MTHFR C677T and A1298C gene polymorphisms and hyperhomocysteinemia as risk factors of diabetic nephropathy in type 2 diabetes patients. Diabetes Res. Clin. Pract. 2007, 75, 99-106. [CrossRef] [PubMed]

33. Benrahma, H.; Abidi, O.; Melouk, L.; Ajjemami, M.; Rouba, H.; Chadli, A.; Oudghiri, M.; Farouqui, A.; Barakat, A. Association of the C677T polymorphism in the human methylenetetrahydrofolate reductase (MTHFR) gene with the genetic predisposition for type 2 diabetes mellitus in a Moroccan population. Genet Test Mol. Biomark. 2012, 16, 383-387. [CrossRef]

34. Poodineh, M.; Saravani, R.; Mirhosseini, M.; Sargazi, S. Association of Two Methylenetetrahydrofolate Reductase Polymorphisms (rs1801133, rs1801131) with the Risk of Type 2 Diabetes in South-East of Iran. Rep. Biochem. Mol. Biol. 2019, 8, 178-183. [PubMed]

35. Ericson, U.C.; Ivarsson, M.I.; Sonestedt, E.; Gullberg, B.; Carlson, J.; Olsson, H.; Wirfalt, E. Increased breast cancer risk at high plasma folate concentrations among women with the MTHFR 677T allele. Am. J. Clin. Nutr. 2009, 90, 1380-1389. [CrossRef] [PubMed]

36. Karimian, M.; Hosseinzadeh Colagar, A. Human MTHFR-G1793A transition may be a protective mutation against male infertility: A genetic association study and in silico analysis. Hum. Fertil. 2018, 21, 128-136. [CrossRef] [PubMed]

37. Hazra, A.; Wu, K.; Kraft, P.; Fuchs, C.S.; Giovannucci, E.L.; Hunter, D.J. Twenty-four non-synonymous polymorphisms in the one-carbon metabolic pathway and risk of colorectal adenoma in the Nurses' Health Study. Carcinogenesis 2007, 28, 1510-1519. [CrossRef]

38. Du, Y.F.; Luo, W.P.; Lin, F.Y.; Lian, Z.Q.; Mo, X.F.; Yan, B.; Xu, M.; Huang, W.Q.; Huang, J.; Zhang, C.X. Dietary choline and betaine intake, choline-metabolising genetic polymorphisms and breast cancer risk: A case-control study in China. Br. J. Nutr. 2016, 116, 961-968. [CrossRef] [PubMed]

39. Azzini, E.; Ruggeri, S.; Polito, A. Homocysteine: Its possible emerging role in at-risk population groups. Int. J. Mol. Sci. 2020, 21, 1421. [CrossRef]

40. Ogier de Baulny, H.; Gerard, M.; Saudubray, J.M.; Zittoun, J. Remethylation defects: Guidelines for clinical diagnosis and treatment. Eur. J. Pediatr. 1998, 157, S77-S83. [CrossRef]

41. Lee, J.E.; Jacques, P.F.; Dougherty, L.; Selhub, J.; Giovannucci, E.; Zeisel, S.H.; Cho, E. Are dietary choline and betaine intakes determinants of total homocysteine concentration? Am. J. Clin. Nutr. 2010, 91, 1303-1310. [CrossRef]

42. Wang, H.; Hu, C.; Xiao, S.H.; Wan, B. Association of tagging SNPs in the MTHFR gene with risk of type 2 diabetes mellitus and serum homocysteine levels in a Chinese population. Dis. Markers 2014, 2014, 725731. [CrossRef] 